\title{
Strain Differences in Virulence of Group B Streptococci
}

\author{
JOSE IGNACIO SANTOS, ANN O. SHIGEOKA, AND HARRY R. HILL ${ }^{(24)}$ \\ Division of Clinical Immunology and Allergy, Department of Pediatrics [J. I. S., A. O. S., H. R. H.], University of \\ Utah, College of Medicine, Salt Lake City, Utah, USA
}

\begin{abstract}
Summary
Strain differences in virulence for types Ia, II and III group B streptococci were assessed using an animal model of group B streptococcal disease. Human isolates of group B streptococci, which have been shown to have strain specific differences in opsonic requirements, were also found to exhibit differences in virulence within the same serotype. Serum, possessing opsonic and protective antibody against one strain, often did not have activity against other strains of the same serotype. Our results point to a direct correlation between strain resistance to opsonization and increased virulence within a given serotype.
\end{abstract}

\section{Speculation}

Some strains of group B streptococci appear to be more virulent than others in experimental animals. These strains are not uniformly susceptible to the action of antibody and complement. Such strain differences in virulence and opsonic requirements must be considered in the development of active or passive immunotherapy of this most fulminant of neonatal diseases.

Group B streptococci continue to be a major cause of morbidity and mortality in neonates and in other patients with compromised host defense mechanisms $(2,13)$. In previous studies we have shown strain specific differences in opsonic requirements for type II and III group B streptococci $(8,18)$. Using a chemiluminescence opsonic assay (6), a radiolabeled bacterial uptake technique (1), and an indirect immunofluorescence method (6), we have systematically examined a number of sera for opsonic activity to multiple strains of group B streptococci isolated from infected infants. We found some strains to be highly resistant to opsonization by antibody containing serum (18). The strains which have this pattern of resistance to opsonization are considered to be resistant strains. In contrast to these isolates, other strains are opsonized by the majority of antibody containing sera examined and are considered sensitive strains $(8,18)$.

The purpose of this study was to assess the biologic significance of these differences in opsonic requirements using an animal model of group B streptococcal disease. Resistance to opsonization was found to correlate closely with virulence.

\section{MATERIALS AND METHODS}

Preparation of organisms. Human isolates of group B streptococci, types Ia, II, and III sensitive (S) or resistant (R) to opsonization by most antibody containing $\left(\mathrm{Ab}^{+}\right)$sera were cultured in Todd-Hewitt (Difco Laboratories, Detroit, MI) broth at $37^{\circ} \mathrm{C}$ for $14 \mathrm{~h}$ and adjusted to $1 \times 10^{9} \mathrm{cfu}$ per $\mathrm{ml}$ in phosphate buffered saline (PBS) as previously described (6). These organisms were used immediately for infecting the newborn rats.

Serum treatment. Fresh serum or serum frozen immediately after collection at $-70^{\circ} \mathrm{C}$ was assessed for opsonic activity by a chemiluminescence and a radiolabeled bacterial uptake technique and for antibody by indirect immunofluorescence $(1,6)$. Over 20 different sera were employed in these studies. Representative experiments are shown. For opsonic assays, sera was heated at $56^{\circ} \mathrm{C}$ for $1 \mathrm{~h}$ and then reconstituted with whole human complement as previously described (6).

Rabbit antibody to the group specific carbohydrate of group B organisms was purchased from Difco Laboratories (Detroit, MI). Typing serum was prepared by slight modifications of Lancefield's techniques as previously described (6). All sera were absorbed with equal volumes of heterologous type organisms to remove cross reactions (6).

Chemiluminescence procedure. This procedure has been described in detail elsewhere (6). Briefly, sera to be tested for opsonic antibody activity were incubated at $37^{\circ} \mathrm{C}$ for $30 \mathrm{~min}$ with a reference or wild type (recent clinical isolate) strain of group B streptococci types Ia, II, or III at a ratio of $0.5 \mathrm{ml}$ of bacteria (át $5.0 \times 10^{8}-1.0 \times 10^{9}$ colony-forming units per $\mathrm{ml}$ ) to $0.1 \mathrm{ml}$ of serum. The opsonized bacteria were washed thoroughly to remove unbound antibody. In dark adapted scintillation vials, polymorphonuclear leukocytes $\left(0.5 \mathrm{ml}\right.$ at $10^{7}$ cells $\left./ \mathrm{ml}\right)$ were mixed with $0.5 \mathrm{ml}$ of the bacterial suspension. The volume was adjusted to 3.5 $\mathrm{ml}$ with sterile PBS. The vials were capped, and placed in a Beckman LS-100c liquid scintillation counter (Beckman Instruments, Inc., Fullerton, CA) and counted at approximately $10 \mathrm{~min}$ intervals for a total of $100 \mathrm{~min}$. Chemiluminescence (CL) peaks of $7500 \mathrm{cpm}$ or greater were always associated with phagocytic uptake as determined by visual microscopic examination (6), which was performed as described below. Phagocytic uptake was also assessed in selected sera by the radiolabeled bacterial uptake technique described below (1). The correlation coefficient between $C L$ peaks and accumulated cpm approximates 0.79 . It should be noted that the level of chemiluminescence, which indicates the presence of functional opsonic antibodies in these studies, is higher than in previously published reports (6) and reflects a higher overall background from an older scintillation apparatus. Thus, bacterial uptake using the visual and radiolabeled technique was associated with CL peaks of 7500 rather than $6500 \mathrm{cpm}$.

Visual microscopic examination of reaction mixtures. After scintillation counting, each reaction mixture was centrifuged at 5000 rpm for $5 \mathrm{~min}$, the supernate was removed, and the cell button was resuspended in a small volume of PBS. An aliquot of this mixture was placed on a clean microscope slide and air dried. The slides were fixed for $10 \mathrm{~min}$ in $100 \%$ methanol and stained with Giemsa (Harleco, Gibbstown, NJ, 1:50 in distilled water) for $1 \mathrm{~h}$. Each slide was examined microscopically under oil immersion to visually assess phagocytosis of the organisms.

Radiolabeled bacterial uptake technique. Bacteria were prepared by incubation on Todd-Hewitt media containing $\left[{ }^{3} \mathrm{H}\right]$-leucine $(5$ $\mathrm{mCi} / \mathrm{ml}$ ) at $37^{\circ} \mathrm{C}$ for $24 \mathrm{~h}$, heat-killed, washed 3 times in PBS and adjusted to $3.3 \times 10^{8} \mathrm{cfu} / \mathrm{ml}$ (1). Aliquots of bacteria were stored at $-20^{\circ} \mathrm{C}$ prior to use and at that time opsonized at $37^{\circ} \mathrm{C}$ for 30 min as described above. Opsonized bacteria were washed once and resuspended to the original volume in medium 199 (Microbiological Associates, Walkersville, MD). Phagocytic uptake by 
human polymorphonuclear leukocytes (PMN) was determined by a modification of the method previously described by Mandel (14) and Anthony and coworkers (3). Monolayers of PMN were prepared by incubating $0.3 \mathrm{ml}$ leukocyte suspension on $18 \times 18 \mathrm{~mm}$ glass coverslips at room temperature for $30 \mathrm{~min}$. Nonadhering cells were washed off with PBS and $0.3 \mathrm{ml}\left(1 \times 10^{8}\right.$ organisms) of the opsonized, labeled bacterial suspensions added to each coverslip. Control suspensions contained bacteria alone, PMNs alone and unopsonized bacteria plus PMN. At intervals of 1, 10, 20, 30, 40 , and $50 \mathrm{~min}$, coverslips were washed with PBS, placed in scintillation vials with $5.0 \mathrm{ml}$ of Aquasol and counted $5 \mathrm{~min}$ in a Beckman LS-100c scintillation counter. The monolayers appeared evenly distributed by microscopic examination. The number of adherent cells $\left(5 \times 10^{5}-1.5 \times 10^{6}\right)$ was estimated by counting cells in 5 random grids at 400 power and multiplying the average by the number of grids (20227) per coverslip. The accumulated cpm/ $10^{6}$ adherent PMNs were calculated at each interval and plotted against time. Controls were bacterial suspensions added to coverslips without cell monolayers or with cells but unopsonized bacteria and showed no accumulation of radioactivity.

Preparation of group B streptococcal antigen. Cold trichloroacetic acid extracts of the reference strains of group B streptococci were prepared by slight modifications of the procedures of Lancefield $(9,10)$ and Lancefield and Freimer (11). Briefly, strains were inoculated into enriched Todd-Hewitt broth as described by Baker and Kasper (4), and incubated at $37^{\circ} \mathrm{C}$ for $18 \mathrm{~h}$. The bacterial pellet was then extracted in $2.5 \%$ cold trichloroacetic acid (TCA) in an ice water bath with sonication. Such mild treatment with TCA does not significantly alter the sialic acid content of saline or buffer extracted antigen (21). The type specific antigens were then separated from group specific substances by fractional alcohol precipitation utilizing 1.5 volumes of alcohol. All extracts were examined for the presence of type specific and group specific substances by capillary precipitin (10) and counterimmunoelectrophoresis (7).

Semi-quantitative capillary precipitin procedure and counterimmunoelectrophoresis (CIE). The capillary precipitin tests were performed by mixing equal volumes of absorbed rabbit hyperimmune type-specific antiserum and the antigen to be tested in sterile capillary tubes (10). Typing reactions were read in $10 \mathrm{~min}$; formation of a precipitate was interpreted as a positive test. Varying dilutions of the antigen mixtures were used in an effort to roughly quantitate the type-specific antigen present. The final dilution of an extract yielding a precipitin band with a standard serum was used as an estimate of the relatively quantity of the antigen present in the undiluted extract. In these experiments, strains were grown for $18 \mathrm{~h}$ in Todd-Hewitt broth $(250 \mathrm{ml})$ and adjusted to an optical density of 0.7 at $620 \mathrm{~nm}$. The bacterial pellet was then extracted with a standard volume of cold $2.5 \%$ TCA as described above. Standardized volumes of the extracts were used in the capillary precipitin tests and the CIE procedure.

Counterimmunoelectrophoresis of standardized broth culture filtrates or extracts of organisms were performed as described by Hill and coworkers (7). Type II and III $\mathbf{R}$ and $\mathbf{S}$ strains were grown in enriched Todd-Hewitt broth, adjusted to a standard optical density and the culture filtrate or TCA extracted antigens were tested by CIE. Standard absorbed rabbit typing antisera against type II or III was placed in the well nearest the anode while the culture filtrates were diluted and placed in the well nearest the cathode. Electrophoresis was carried out for $30 \mathrm{~min}$ at 5-7 mA per $1 \times 3$ inch microscope slide. Slides were then incubated in the cold overnight and examined the next day with a hand lens. The highest dilution of extract produce a detectable precipitate with a standard antiserum is used as an estimate of the quantity of the antigen present.

Neonatal rat infections. Outbred neonatal Sprague-Dawley rats were studied within $12 \mathrm{~h}$ from the time of birth. Animals were inoculated intraperitoneally with $5 \mu$ l of PBS containing $5 \times 10^{6}$ streptococci. In the protection studies, the animals also received separate equal volume injections of serum. The rat litters were observed at 6-h intervals for mortality. Surviving rats were observed for a total of $3 \mathrm{wk}$ as previously described (16).

Statistical analysis. Comparison of significance of differences between survival values in the animal studies was performed by use of the Fisher Exact test.

\section{RESULTS}

The survival rate in 28 unprotected rats infected with a strain of type III group B streptococci which was sensitive (S) to opsonization by most serum containing antibody as determined by indirect immunofluorescence was $29 \%$. In contrast, animals who received a strain of type III group B streptococci, which was resistant to opsonization had a $100 \%$ mortality (Fig. 1). Similar differences in host susceptibility to sensitive and resistant strains of type Ia and type II group B streptococci were also demonstrated and are depicted in Fig. 2; thus, resistance to opsonization appears to be associated with increased virulence in this animal model.

Because the type specific polysaccharide has been shown to be one of the antiphagocytic or virulence factors of group B streptococci, we next measured the capsular polysaccharide content of human isolates of sensitive and resistant strains of types Ia, II and III group B streptococci by the quantitative capillary precipitin test and CIE using standardized extracts of the strains prepared as described under methods. Type specific, cross absorbed rabbit antiserum was used in hese semiquantitative studies. Ten human isolates of group B streptococci were evaluated. As shown in Table 1 , some sensitive strains with low virulence exhibited a high polysaccharide content as determined by the precipitin titer whereas some resistant strains with high virulence exhibited a low polysaccharide content. Thus, we could not demonstrate an association between extractable capsular polysaccharide content and virulence in this animal model. Additional studies (Table 1) failed to show a difference in the amount of type specific or group B polysaccharide released into the growth media between sensitive and resistant strains (as determined by CIE precipitin analysis with standard absorbed antisera).

The effect of antibody on the virulence of these strains was determined next. The survival rate in 39 neonatal rats infected with type IIIS group B streptococci who received human serum containing antibody directed against the organism by indirect immunofluorescence antigen was $65 \%$. In contrast, none of the type IIIR infected animals who received the same human serum survived (Fig. 3 ). The $R$ strain was also coated with antibody as determined by the indirect immunofluorescence assay. We also evaluated the susceptibility of the $R$ and $S$ strain to opsonization by this same antibody containing serum using the chemiluminescence assay. A significant difference in chemiluminescence pro-

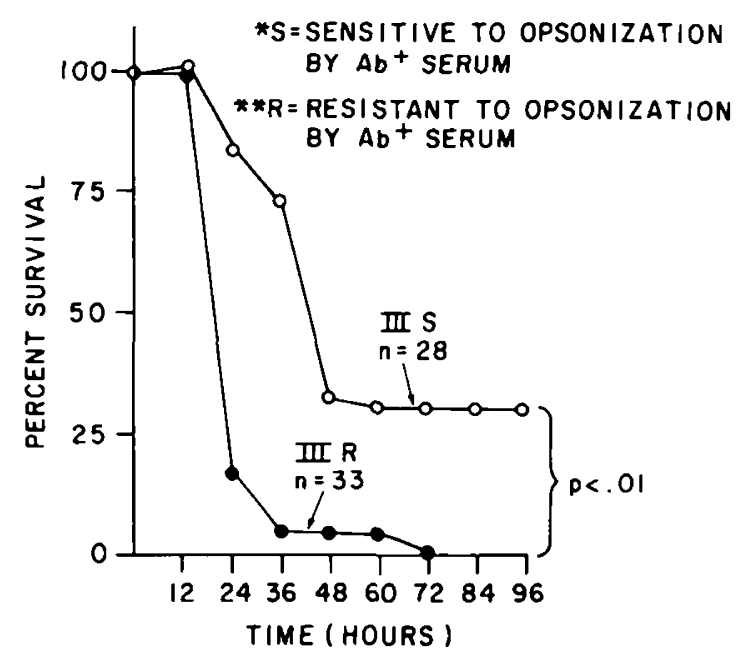

Fig. 1. Host susceptibility to sensitive (S) and resistant (R) strains of type III group B streptococci. $n=$ number of rats infected. 

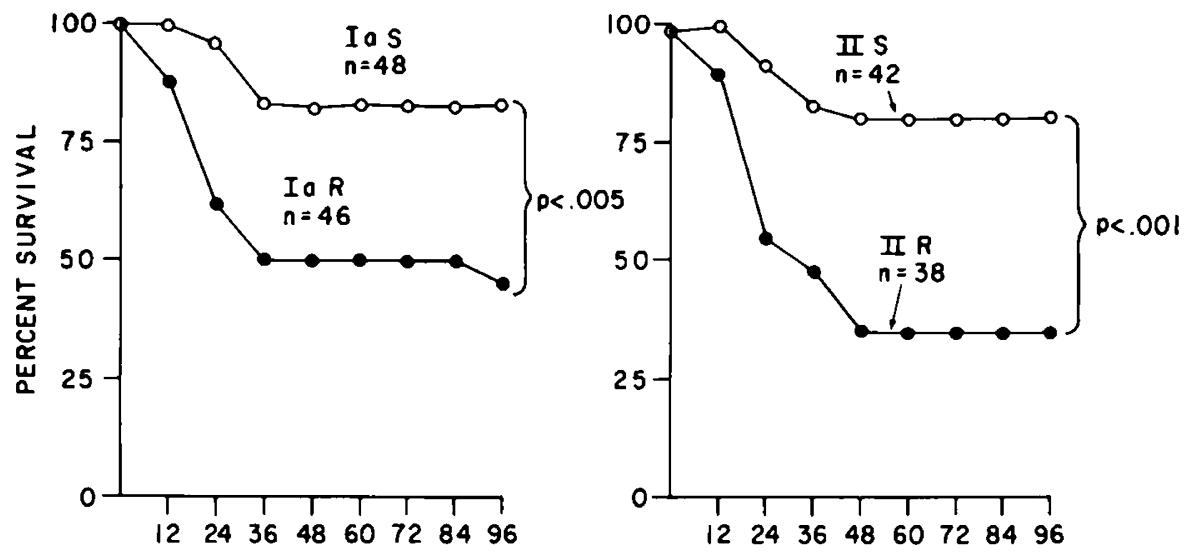

TIME (HOURS)

Fig. 2. Host susceptibility to sensitive (S) and resistant (R) strains of type Ia and type II group B streptococci. $n=$ number of rats infected.

Table 1. Typing polysaccharide production by sensitive and resistant strains

\begin{tabular}{|c|c|c|c|c|c|c|c|c|}
\hline \multirow[b]{2}{*}{ Patient } & \multirow[b]{2}{*}{ Disease } & \multirow[b]{2}{*}{ Outcome } & \multirow[b]{2}{*}{ Strain } & \multicolumn{2}{|c|}{ Animal group } & \multicolumn{3}{|c|}{ Type specific antigen production (titer) } \\
\hline & & & & $\mathrm{N}$ & $\%$ mortality & Capillary PPT $^{3}$ & CIE & $\begin{array}{c}\begin{array}{c}\text { Released anti- } \\
\text { gen }\end{array} \\
\mathrm{CIE}\end{array}$ \\
\hline 1 & $\mathrm{EO}^{1}$ & Died & la $S$ & 48 & 20 & $1: 4$ & $1: 64$ & $1: 1$ \\
\hline 2 & EO & Died & la $\mathbf{R}$ & 46 & 50 & $1: 4$ & $1: 64$ & $1: 1$ \\
\hline 5 & EO & Died & II $\mathbf{R}$ & 38 & 65 & $1: 16$ & $1: 64$ & $1: 4$ \\
\hline 6 & EO & Survived & II $\mathbf{R}$ & 38 & 33 & $1: 32$ & $1: 32$ & $1: 4$ \\
\hline 7 & $\mathrm{LO}^{2}$ & Survived & III S & 28 & 75 & $1: 16$ & $1: 32$ & $1: 16$ \\
\hline 8 & EO & Survived & III S & 34 & 60 & $1: 32$ & $1: 8$ & $1: 8$ \\
\hline 9 & EO & Died & III R & 28 & 100 & $1: 64$ & $1: 64$ & $1: 8$ \\
\hline 10 & EO & Survived & III $R$ & 33 & 100 & $1: 32$ & $1: 128$ & $1: 8$ \\
\hline
\end{tabular}

${ }^{1} \mathrm{EO}=$ Early onset disease.

${ }^{2} \mathrm{LO}=$ Late onset disease

${ }^{3} \mathrm{PPT}=$ Precipitin.

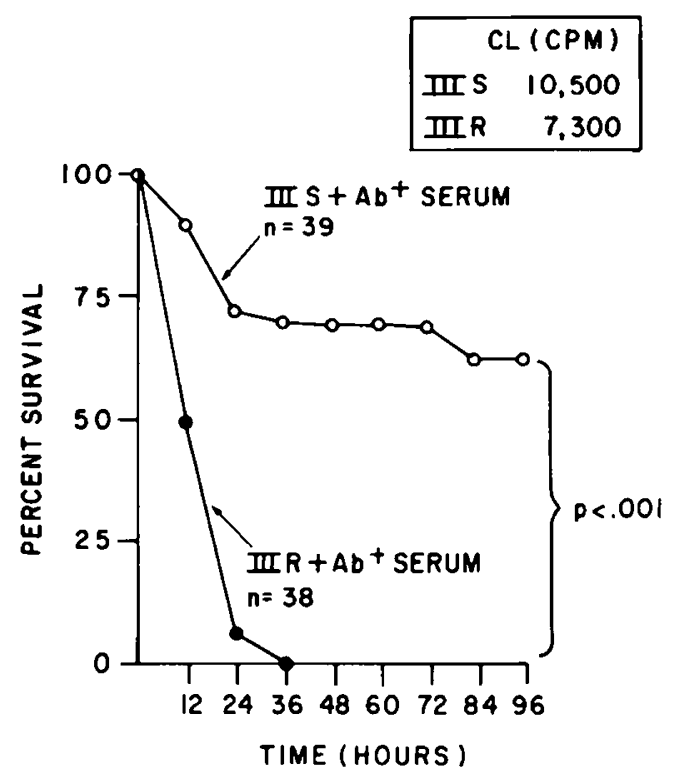

Fig. 3. Effect of antibody containing serum on neonatal rat survival with type IIIS and IIIR group B streptococcal infection. $\boldsymbol{n}=$ number of rats infected. duction was observed when control PMNs were challenged with the preopsonized IIIS strain $(10,500 \mathrm{cpm})$ compared to the preopsonized IIIR strain (7,300 cpm) (Fig. 4). Phagocytic uptake as determined by radiolabeled bacterial uptake and visual microscopic examination was associated with peak CL values of 7,500 cpm or greater in these experiments (see "Materials and Methods"). Thus, the serum contained excellent opsonic and protective antibody against one type III strain but did not have activity against another strain of the same serotype. These results are representative of those obtained with 12 additional human sera possessing similar activity.

After examining a number of human sera, three were found which did opsonize the IIIR strain. The peak $C L$ value with the IIIR strain opsonized in a representative serum sample from this group was 8500 (Fig. 4). This serum offered protection in the neonatal rats infected with the IIIR strain when compared to the unprotected group $(P<0.002)$.

\section{DISCUSSION}

Our results indicate that human isolates of group B streptococci, types Ia, II and III which have specific differences in opsonic requirements also exhibit differences in virulence within the same serotype when tested in this animal model. The virulence of $S$. pneumoniae (15) and Hemophilus influenzae type b (20) appears to 


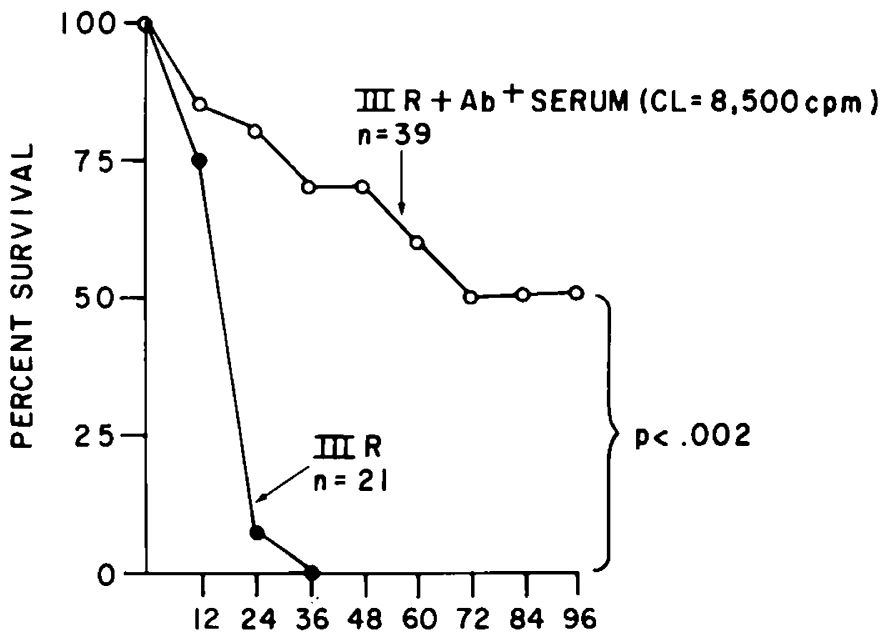

TIME (HOURS)

Fig. 4. Effect of antibody containing serum on neonatal rat survival with type IIIR group B streptococcal infection. $n=$ number of rats infected. This serum possessed excellent opsonic activity for the IIIR strain $(\mathrm{Cl}=$ $8500 \mathrm{cpm})$.

be associated with thicker capsules and the amount of physically integrated capsular polysaccharide. Presumably the amount of capsular polysaccharide increases resistance to opsonization and blood serum, clearance. Strains of group B streptococci are known to vary in their content of type specific antigen and in some instances are missing this substance (10). Previous studies with group B streptococci have failed to show a correlation between capsular polysaccharide content and susceptibility to opsonization by antibody containing sera (18). Similarly, we found no correlation between virulence and capsular polysaccharide content of individual strains of the same serotype. Neither could we demonstrate differences in the amount of type specific antigen released into the growth media by relatively virulent or nonvirulent strains. These results indicate that, in this animal model, group B streptococcal type specific polysaccharide content or release is not directly related to the strain's virulence, nor does it directly relate to resistance to opsonization.

Protection against group B streptococci presumably depends on opsonic antibodies specific for surface polysaccharides and protein antigens that occur in the five serotypes $(11,12,19)$. Serum absorption studies with TCA and hot $\mathrm{HCl}$ extracts remove some but not all opsonins to these organisms $(6,11,12)$. Our previous studies $(17,18)$ with whole organisms and type III carbohydrate extracts indicate that antibody to type specific polysaccharide is important in opsonizing both serum resistant and serum sensitive strains. It is not the only antibody important in opsonization and protection, however. Fischer and coworkers (5) have recently shown that antibody to the type-specific antigen of type III group B streptococci opsonizes some but not all type III strains. Similarly, the present studies indicate that serum possessing excellent opsonic and protective antibody against one strain often did not have protective activity against other strains of the same serotype (at least 12 different sera). Our results in this animal model also point to a direct correlation between strain resistance to opsonization and increased virulence within a given serotype. These critical differences in opsonic requirements of the various strains and the variation in protective efficacy of antibody directed against different components of group B organisms must be considered in any attempt at providing active or passive immunity to the neonate.

\section{REFERENCES AND NOTES}

1. Allred, C. D., Shigeoka, A. O., and Hill, H. R.: Evaluation of group B streptococcal opsonins by radiolabeled bacterial uptake technique. J. Immunol. Methods 26: 355 (1979).

2. Anthony, B. F. and Concepcion, N. F.: Group B streptococcus in a general hospital. J. Infec. Dis. 132: 561 (1975).

3. Anthony, B. F.: Immunity to the group B streptococci: interaction of serum and macrophages with types Ia, Ib, and Ic. J. Exp. Med., 143: 1186 (1976).

4. Baker, C. J. and Kasper, D. L.: Microcapsule of type III strains of group B streptococcus: production and morphology. Infect. Immun., 13: 189 (1976)

5. Fischer, G. W., Hunter, K. W., and Wilson, S. R.: Type III group B streptococcal strain differences in susceptibility to opsonization to human serum. Pediatr. Res. (In Press).

6. Hemming, V. G., Hall, R. T., Rhodes, P. G., Shigeoka, A. O., and Hill, H. R. Assessment of group B streptococcal opsonins in human and rabbit serum by neutrophil chemiluminescence. J. Clin. Invest., 58: 1379 (1976).

7. Hill, H. R., Riter, M. E., Menge, S. K., Johnson, D. R., and Matsen, J. M.: Rapid identification of group B streptococci by counterimmunoelectrophoresis. J. Clin. Micro., 1 : 188 (1975).

8. Hill, H. R., Shigeoka, A. O., Hall, R. T., and Hemmint, V. G.: Neonatal cellular and humoral immunity to group B streptocci. Pediatrics, 64: 5787 (1979).

9. Lancefield, R. C.: A serological differentiation of specific types of bovine hemolytic streptococci (group B). J. Exp. Med., 59: 441 (1934).

10. Lancefield, R. C.: A micro-precipitin-technique for classifying hemolytic streptococci and improved methods for producing antisera. Proc. Soc. Exp. Biol. Med., 38: 473 (1938).

11. Lancefield, R. C. and Freimer, E. H.: Type specific polysaccharide antigens of group B streptococci. J. Hyg., 64: 191 (1966).

12. Lancefield, R. C., McCarty, M., and Everly, W. N.: Multiple mouse-protective antibodies directed against group B Streptococci: special reference to antibodies effective against protein antigens. J. Exp. Med., 142: 165 (1975).

13. Lerner, P. I., Gopalakrishna, K. V., Solinsky, E., McHerny, M. C., Tan, J. S., and Rosenthal, M.: Group B streptococcus ( $S$. agalacticae) bacteremia in adults: analysis of 32 cases and a review of the literature. Medicine, 55: 457 (1977).

14. Mandel, G. L.: Effect of temperature on phagocytosis by human polymorphonuclear neutrophils. Infect. Immunol. 12: 221 (1975).

15. McCarty, M.: Pneumococci. In: Davis, B. C., Dulbeco, R., Eisen, H. N., Ginsberg. H. S., and Wood, W. B., Jr., Eds., Microbiology, pp 49-65 (Harper and Row, Hagerstown, MD, 1973)

16. Santos, J. I., Shigeoka, A. O., and Hill, H. R.: Functional leukocyte administration against experimental neonatal infection. Pediatr. Res., 14: 1408 (1980)

17. Shigeoka, A. O., Hall, R. T., Hemming, V. G., Allred, C. D., and Hill, H. R.: Role of antibody and complement in opsonization group B streptococci. Infect. Immun. 21: 34 (1978).

18. Shigeoka, A. O., Hall, R. T., and Hill, H. R.: Strain specificity of opsonins for group B streptococci types II and III. Infect. Immun. 23: 438 (1979).

19. Stewardson-Krieger, P. B., Albrandt, K., Nevin, T., Kretschmer, R. R., and Gotoff, S. P.: Perinatal immunity to group B b-hemolytic streptococcus type Ia. J. Infect. Dis., 136: 649 (1977).

20. Weller, P. F., Smith, A. C., Anderson, P., and Smith, D. H.: The role of encapsulated and host age in the clearance of Haemophilus influenzae bacteremia. J. Inf. Dis., 135: 34 (1978).

21. Wilkinson, H. W.: Immunochemistry of purified polysaccharide type antigens of group B streptococcal types Ia, Ib and Ic. Infection and Immun. 11: 845 (1975).

23. The authors thank Nancy $L$. Taylor for her technical assistance.

24. Requests for reprints should be addressed to: Dr. Harry R. Hill, Division of Clinical Immunology and Allergy, Department of Pediatrics, University of Utah, Salt Lake City, Utah 84132.

25. This research was supported, in part by U.S. Public Health Service Grants AI 13150 and AM 21140 and a grant from the Thrasher Foundation. Dr. Hill is an investigator of the Howard Hughes Medical Institute.

26. Received for publication April 27, 1981.

27. Accepted for publication September 22, 1981 